\title{
Comprehensive Utilization of Ammonia-containing Exhaust Gas in Soda Ash Chemical Plants
}

\author{
Dong Yanping ${ }^{1}, \mathrm{Fu} \mathrm{Lei}^{2}$, Wang Lihui ${ }^{3}$ \\ ${ }^{1}$ Lianhe Taize Environmental Science and Technology Development Co., Ltd. \\ ${ }^{2}$ China Lianhe Equator Environmental Impact Assessment Co., Ltd. \\ ${ }^{3}$ Tianjin Modern Vocational Technology College
}

\begin{abstract}
Industrial chemical plants of soda ash mainly adopted the ammonia-soda production process and the combined process (Hou's process for soda manufacture), during which the mother liquor was recycled and the exhaust gas purified and recovered, realizing continuous manufacturing. However, in practical operation, there was still a small amount of fugitive ammonia emitted during storage and transport of materials. To improve the environment, an idea of using ammonia-containing exhaust gas for process improvement was introduced: collecting the ammonia-containing exhaust gas, extract some of the thin liquid from the circulating mother liquor for preparation of pure water, from which the concentrate return to the mother liquor circulation system and the pure water for absorption of the ammonia-containing gas; dilute ammonia water that took in the ammonia-containing gas and the feedstock ammonia were again used for preparation of ammonia water for industrial use, which, at the service of the boiler desulfurizing installations of the enterprise, helped achieve internal energy saving and emission reduction.
\end{abstract}

\section{Introduction}

According to Report on the 2017-2022 Operation Pattern of China's Soda Ash Industry and its Investment Appraisal under the Thirteenth Five-year Plan from ChinaBaoGao.com, the industrial production of soda ash in China mainly adopted the natural soda process, the ammonia-soda process and the combined process (Hou's process for soda manufacture), of which the latter two accounted for $93.6 \%$. Though the design of exhaust purification and recovery system of soda ash production has developed into a sophisticated process $^{[1]}$, in actual operation, there was still a small amount of fugitive ammonia emitted during storage and transport of materials. To improve the environment, referring to the utilization of denitrified ammonia gas for ammonia water preparation by boilers in thermal power plants, this part of ammoniacontaining exhaust could be used for boiler desulphurization. In this way, both the emission of pungent smells and the operating expenses could be brought down ${ }^{[2]}$.

Taking a soda ash industrial chemical plant using the combined process as example: fugitive emissions of ammonia-containing exhaust were collected, part of the thin liquid from the circulating mother liquor extracted for preparation of pure water, from which the concentrate return to the mother liquor circulation system and the pure water for absorption of the ammonia-containing gas; dilute ammonia water that took in the ammonia-containing gas and the feedstock ammonia were again used for preparation of ammonia water for industrial use, which, at the service of the boiler desulfurizing installations of the enterprise, helped achieve internal energy saving and emission reduction.

\section{Collection and Treatment of Ammonia- containing Exhaust}




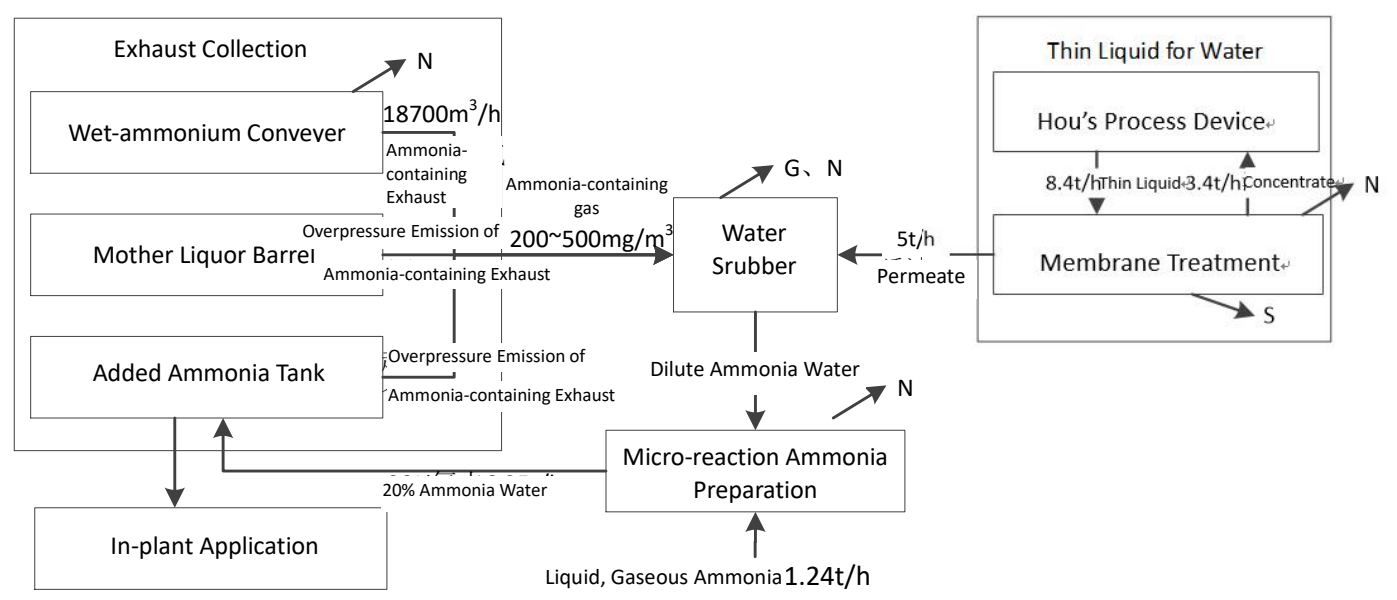

Picture 1 Outline Process Chart of the Treatment Device of Ammonia-containing Gas

Picture 1 is the process chart of collection and treatment of ammonia-containing exhaust gas, mainly including the following aspects:

Collection of ammonia-containing exhaust gas: Seal the wet-ammoniaum belt conveyer with a cover and pressure the exhaust gas in the sealed cover to the water scrubber with the fan; set an overpressure vent valve in the mother liquor barrel in the Hou's processing device, where overpressure exhaust emissions enter the water scrubber through the pipes; the new ammonia water tank added for project construction involves breathing exhaust, which enters the water scrubber through the pipes.

Water production from thin liquid: Balance the mother liquor in Hou's processing device, extract part of the thin liquid from the circulating mother liquor for preparation of pure water, i.e. carbonization; extract part of the thin liquid from thin liquor distillation tower for multi-media filtration and ultrafiltration and then reverse osmosis, after two RO levels, the concentrate returns to Hou's processing device, and the permeate enters the water scrubber as the scrubber water. The process of water production from thin liquid is as shown in picture 2 .

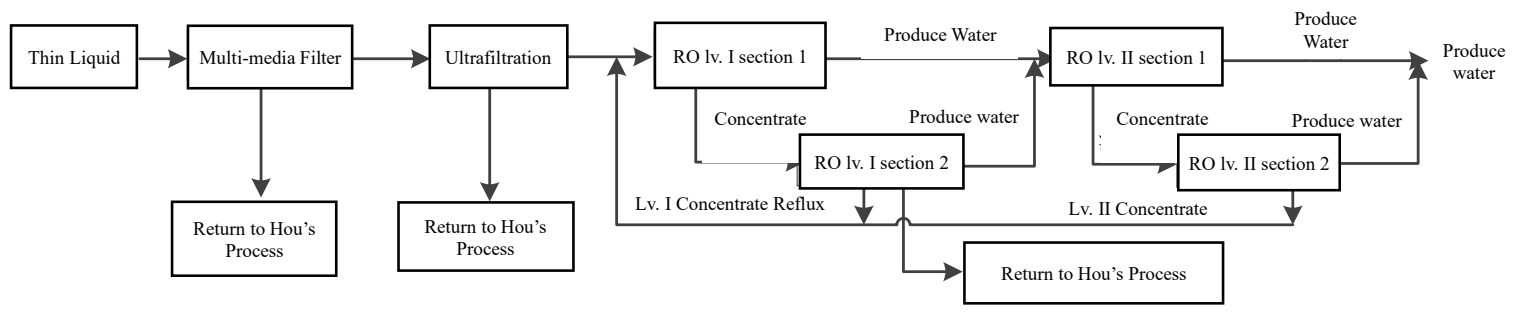

Picture 2 Process of Water Production from Thin Liquid

Exhaust scrubbing: Scrub ammonia-containing exhaust gas in the water scrubber with membrane-treated permeate, repeat the washing and absorbing process till it reaches ammonia solubility and produces dilute ammonia water. Water cycles in the scrubber for washing and exchanges heat outside the scrubber; an induced draft fan keeps the slight negative pressure of the scrubber. Dilute ammonia water is pumped into the micro-reaction preparation part; a small volume of ammonia-containing exhaust is emitted through the chimney.

Preparation of ammonia water: Prepare ammonia water with the safer and more sophisticated microreactor method. Mix the scrubbed dilute ammonia water and the existing feedstock liquid and gaseous ammonia in the plant through the micromixer per a certain flow rate (byproduct: 20\% ammonia solution for industrial use), during which use circulating water for cooling.

\section{Comprehensive Utilization of Materials in Soda Ash Industrial Chemical Plants}

\subsection{Energy Saving and Emission Reducing Effect}

Fugitive emissions of ammonia-containing exhaust gas involved in the project mainly came from the operation of wet-ammonium belt conveyer and the overpressure emission of mother liquor storage barrel. Ammonia content in the exhaust gas was $200 \sim 500 \mathrm{mg} / \mathrm{m}^{3}$, with a fan of the blowing rate of $13000 \mathrm{~m}^{3} / \mathrm{h}, \max$ ammonia processing capacity could reach $6.50 \mathrm{~kg} / \mathrm{h}$. The process was so designed that it would continue circulating and absorbing after water spray till reaching the max ammonia solubility. Exhaust gas left would then be emitted through the $15 \mathrm{~m}$-high chimney at the top of the absorption tower. Ammonia is easily soluble in water; theoretically, 1 unit volume of water could absorb about 378.8 units of ammonia gas; under room temperature, the concentration of ammonia water could reach $25 \% \sim 28 \%$. According to 
experimental experience, the concentration of dilute ammonia water obtained after water spray once was about $0.1 \%$, which could be increased to $1 \%$ after circulating absorption till saturation. Designed water consumption of the project reached $5 \mathrm{t} / \mathrm{h}$. After complete absorption, the concentration of ammonia water was $0.13 \%$. In theory, all the ammonia gas could be absorbed. Set the design target to be the maximum $10 \mathrm{mg} / \mathrm{m}^{3}$, the ammonia emission would be $0.13 \mathrm{~kg} / \mathrm{h}$, absorption efficiency $98 \%$, effectively reducing fugitive ammonia emissions ${ }^{[3]}$.

\subsection{Utilization of Thin Liquid from Mother Liquor}

Mother liquor in Hou's processing device was recycled. Under normal production conditions, mother liquor was balanced. However, in cases of fluctuations in production load, mother liquor should be exported for fear of expansion. Regular extraction of some thin liquid from the mother liquor could maintain its concentration during circulation and help to stabilize the production of soda ash.

\subsection{Application of Ammonia Water}

Ammonia water has been widely used for industrial, agricultural, medical, experimental and other purposes. With respect to industrial chemical plants of soda ash, they needed to purchase ammonia water for adjustment of the $\mathrm{pH}$ value of boiler feed water and desulfurization of boiler flue gas. The use of ammonia-containing exhaust gas for preparation of ammonia water for boilers could effectively save the operating costs of the plant.

\section{Other Environmental Problems during Comprehensive Utilization of Ammonia- containing Exhaust Gas}

\subsection{Air}

Comprehensive utilization of ammonia-containing exhaust gas was a waste gas treatment project. Ammoniacontaining gas produced by Hou's processing device was water scrubbed and emitted, such emissions mainly containing water vapor, air and trace amount of ammonia. According to experimental experience, clear water spray once could only obtain dilute ammonia water of lower concentration. Designed spray water volume should aim for ammonia absorption as complete as possible $\mathrm{e}^{[4]}$.

\subsection{Water}

The production water supply was circulated cooling water, no wastewater emission or other pollutants.

\subsection{Noise}

New sources of noise pollution in the project were mainly noises from fan and pump operation. Noise prevention should be set up at appropriate positions.

\subsection{Solid Wastes}

Solid wastes involved were RO membranes reached maximum service life, packaging materials of reducing agents and scale inhibitors, no environmental risk materials involved.

\subsection{Brief Summary}

Other environmental problems arising from the project implementation were all common environmental issues of general construction projects, which wouldn't have significant negative impacts on project implementation.

\section{Conclusion}

This paper introduced an idea of using ammoniacontaining exhaust gas for process improvement for industrial chemical plants of soda ash: collecting ammonia-containing exhaust gas, extracting from the circulating mother liquor the thin liquid for preparation of pure water, from which the concentrate should return to the circulation system of mother liquor, and the pure water for absorption of ammonia-containing gas; dilute ammonia water that took in the ammonia-containing gas and the feedstock ammonia should again be used for preparation of ammonia water for industrial use, which, at the service of the boiler desulfurizing installations of the enterprise, could help achieve internal energy saving and emission reduction ${ }^{[5]}$.

\section{About the Authors}

Dong Yanping (1982-), female, Tianjin, Master's Degree, mainly engaged in consultation for environmental protection.

Corresponding Author: Wang Lihui,
wanglihui2008@126.com

\section{References}

1. Li Fangbin. Design of Soda Ash Tail Gas Purification and Recovery System [D]. Sichuan University, 2004.

2. Zhang Hongbo, Huang Wanqi, Liu Tao, et al. Application of Ammonia Water Automatically Prepared from Denitrification Ammonia Gas to Power Plants [J]. Industrial Water Treatment, 2018, 38 (11): 112-114.

3. Gabrielli C, Maurin G, Francy-Chausson H, et al. Electrochemical water softening: principle and application [J]. Desalination, 2006, 201 (1): 150-163.

4. Hasson D, Lumelsky V, Greenberg G, et al. Development of the electrochemical scale removal technique for desalination applications [J]. Desalination, 2008, 230 (1): 329-342.

5. Li Minzhe, Chi Juan, Zhan Lan. Study on Microelectrolysis Applied to the Treatment of the Circulating Cooling Water [J]. Industrial Water Treatment, 2006, 26 (2): 39-42. 